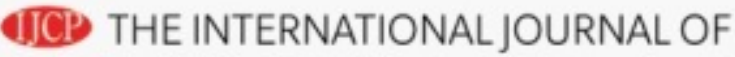 CLINICAL PRACTICE
}

\section{Management Strategies and Clinical Outcomes of Acute Myocardial Infarction in Leukemia Patients: Insights from Nationwide United States Hospitalization}

\begin{tabular}{|r|l|}
\hline Journal: & International Journal of Clinical Practice \\
\hline Manuscript ID & IJCP-09-19-0459.R1 \\
\hline Wiley - Manuscript type: & Original Paper \\
\hline Dute Submitted by the & 12-Dec-2019 \\
\hline Complete List of Authors: & $\begin{array}{l}\text { Mohamed, Mohamed; Keele University, Cardiology } \\
\text { Lopez-Mattei, Juan C.; University of Texas MD Anderson Cancer Center, } \\
\text { Cardiology } \\
\text { Iliescu, Cezar; University of Texas MD Anderson Cancer Center, } \\
\text { Cardiology } \\
\text { Parwani, Purvi; Loma Linda University Medical Center, Cardiology } \\
\text { Bharadwaj, Aditya; University of Texas MD Anderson Cancer Center, } \\
\text { Cardiology } \\
\text { Kim, Peter; University of Texas MD Anderson Cancer Center, Cardiology } \\
\text { Palaskas, Nicolas L; University of Texas MD Anderson Cancer Center, } \\
\text { Cardiology } \\
\text { Rashid, Muhammad; Keele University, Cardiology } \\
\text { Potts, Jessica; Keele University, Cardiology } \\
\text { Kwok, Chun Shing; Keele University, Cardiovascular Research Group } \\
\text { Gulati, Martha; University of Arizona, Cardiology } \\
\text { Al Zubaidi, Abdul Majeed Brek; Mafraq Hospital, Cardiology } \\
\text { Mamas, Mamas A; Keele University, Cardiology }\end{array}$ \\
\hline Specialty area: & \begin{tabular}{l} 
\\
\hline
\end{tabular} \\
\hline
\end{tabular}

\section{SCHOLARONE" Manuscripts}




\section{Management Strategies and Clinical Outcomes of Acute Myocardial Infarction in Leukemia Patients: Insights from Nationwide United States Hospitalizations}

Short Title: AMI outcomes and management in Leukemia patients

Mohamed O. Mohamed ${ }^{1,2}$, Juan C. Lopez-Mattei ${ }^{3}$, Purvi Parwani ${ }^{4}$, Cezar A. Iliescu ${ }^{3}$, Aditya Bharadwaj $^{4}$, Peter Y. Kim ${ }^{3}$, Nicolas L. Palaskas ${ }^{3}$, Muhammad Rashid ${ }^{1}$, Jessica Potts ${ }^{1}$, Chun Shing Kwok ${ }^{1}$, Martha Gulati ${ }^{5}$, Abdul Majeed Brek Al Zubaidi ${ }^{6}$, Mamas A. Mamas ${ }^{1,2,7}$

1. Keele Cardiovascular Research Group, Centre for Prognosis Research, Institutes of Applied Clinical Science and Primary Care and Health Sciences, Keele University, UK

2. Department of Cardiology, Royal Stoke Hospital, University Hospital North Midlands, Stoke-on-Trent, UK

3. Department of Cardiology, Division of Internal Medicine, University of Texas MD Anderson Cancer Center, Houston, TX, USA

4. Division of Cardiology, Loma Linda University, Loma Linda, California, USA

5. Division of Cardiology, University of Arizona, Phoenix, AZ, USA

6. Department of Cardiology, Al Mafraq Hospital, Abu Dhabi, UAE

7. Institute of Population Health, University of Manchester, UK.

\section{Correspondence to:}

Mamas A. Mamas

Professor of Cardiology

Keele Cardiovascular Research Group,

Centre for Prognosis Research,

Institute for Primary Care and Health Sciences,

Keele University, UK

mamasmamas1@yahoo.co.uk

Word count (abstract): 3697

Word count (text, excl. references): 3616

Key Words: Leukemia, Acute myocardial infarction, outcomes, treatments 

Abbreviations
ACS
Acute coronary syndrome
AHRQ
Agency for Healthcare Research and Quality
ALL
Acute Lymphoid Leukemia
AMI
Acute Myocardial Infarction
AML
Acute Myeloid Leukemia
CABG
Coronary Artery Bypass Grafting
CLL
Chronic Lymphoid Leukemia
CML
Chronic Myeloid Leukemia
CVA
Cerebrovascular Accident
MACCE
Major Adverse Cardiovascular and Cerebrovascular
Event
NSTEMI
Non-ST-elevation myocardial infarction
OR
Odds Ratio
PCI
Percutaneous Coronary Intervention
STEMI
ST-elevation myocardial infarction 
Abstract

Background: Patients with leukemia are at increased risk of cardiovascular events. There are limited outcomes data for patients with a history of leukemia who present with an acute myocardial infarction (AMI).

Methods: We queried the Nationwide Inpatient Sample (2004-2014) for patients with a primary discharge diagnosis of AMI, and a concomitant diagnosis of leukemia, and further stratified according to the subtype of leukemia. Multivariable logistic regression was conducted to identify the association between leukemia and major acute cardiovascular and cerebrovascular events (MACCE; composite of mortality, stroke and cardiac complications) and bleeding.

Results: Out of 6,750,878 AMI admissions, a total of 21,694 patients had a leukemia diagnosis. The leukemia group experienced higher rates of MACCE (11.8\% vs. $7.8 \%)$, mortality $(10.3 \%$ vs. 5.8\%) and bleeding (5.6\% vs. 5.3\%). Following adjustments, leukemia was independently associated with increased odds of MACCE (OR 1.26[1.20,1.31]) and mortality (OR $1.43[1.37,1.50])$ without an increased risk of bleeding (OR 0.86[0.81,0.92]). Acute myeloid leukemia (AML) was associated with approximately three-fold risk of MACCE (OR 2.81[2.51, 3.13]) and a four-fold risk of mortality (OR 3.75[3.34, 4.22]). Patients with leukemia were less likely to undergo coronary angiography (CA) $(48.5 \%$ vs. $64.5 \%)$ and percutaneous coronary intervention (PCI) (28.2\% vs. $42.9 \%)$ compared to those without leukemia.

Conclusion: Patients with leukemia, especially those with AML, are associated with poor clinical outcomes after AMI, and are less likely to receive CA and PCI compared to those without leukemia. A multi-disciplinary approach between cardiologists and hematology oncologists may improve the outcomes of patients with leukemia after AMI. 


\section{What is known about this topic?}

-Little is known about the prevalence of leukemia amongst patients presenting with AMI.

-There are inconsistencies in current evidence on outcomes and management strategies of AMI in patients with leukemia.

\section{What does this article add?}

-We report the prevalence of patients with leukemia presenting with acute myocardial infarction from a nationwide analysis for the first time in literature.

-A diagnosis of leukemia, especially the acute myeloid type, is independently associated with worse clinical outcomes in the context of AMI.

-Patients with leukemia are less likely to be offered invasive coronary imaging and intervention after acute myocardial infarction (AMI).

-The study emphasizes the need for a multidisciplinary approach to the management of patients with leukemia, involving both hemoncologists and cardiologists. 


\section{Introduction}

As of 2018, leukemia is the tenth most common type of cancer in the United States, with a reported incidence of 13.8 per 100,000 with an average rise of $0.3 \%$ in new cases per year over the last decade. 1 It is estimated that 1 in 64 men and 1 in 94 women will be diagnosed with leukemia during their lifetime. 2 The survival of leukemia patients has improved in recent years due to improvement in both diagnostic and therapeutic modalities. However, this improvement in life expectancy has led to an increase in the burden of cardiovascular disease in these patients.

Leukemias are classified on the basis of cellular phenotype and degree of differentiation on initial presentation, with the most common subtypes being acute lymphoblastic (ALL), acute myeloid (AML), chronic lymphocytic (CLL), and chronic myeloid (CML) leukemias. Each subtype of leukemia is different in terms of clinical course and outcomes, particularly in relation to risk of thrombotic and major bleeding complications. The pathogenesis of vascular complications in leukemia is complex and multifactorial. The pathophysiologic mechanisms include leukostasis, anemia, depletion of circulating anticoagulants, and the use of chemotherapeutic agents. 3 Despite the fact that the majority of vascular thrombotic phenomena affect the pulmonary and central nervous systems, acute myocardial infarction is well recognized in leukemia patients. $\underline{3-5}$

To date, there is no literature on the prevalence of leukemia amongst patients presenting with acute myocardial infarction (AMI). Furthermore, there is little data on the outcomes of these patients, given the exclusion of patients with active malignancy in cardiovascular randomized trials. $\underline{6}$ The current literature is limited to isolated case reports and reviews, $\underline{4} \underline{5}, \underline{7-}$ $\underline{9}$ without a detailed study on the clinical characteristics, treatments and outcomes of AMI in leukemia patients including among different leukemia subtypes. 
The current study utilized a large contemporary cohort drawn from the National Inpatient Sample from 2004 to 2014 to evaluate the association between a leukemia diagnosis and clinical outcomes of AMI. The study was designed to examine the clinical characteristics, processes of care, economic burden and in-hospital outcomes stratified by both the presence of leukemia and leukemia subtype.

\section{Methods}

\section{Data Source}

The National Inpatient Sample (NIS), is the largest publicly available all-payer database of hospitalized patients in the United States and is sponsored by the Agency for Healthcare Research and Quality (AHRQ) as a part of the Healthcare Cost and Utilization Project.10 It includes anonymized data on primary and secondary discharge diagnoses and procedures from more than 7 million hospitalizations annually. The NIS dataset was designed to approximate $20 \%$ stratified sample of United States community hospitals and provides sampling weights to calculate national estimates that represent more than $95 \%$ of the US population. The estimates of hospital characteristics, numbers of discharges, length of stay, and in-hospital mortality from the HCUP Nationwide Inpatient Sample (NIS) for 2007 were highly comparable to three related data sources: the American Hospital Association (AHA) Annual Survey Database, the National Hospital Discharge Survey (NHDS) from the National Center for Health Statistics, and the MedPAR inpatient data from the Centers for Medicare and Medicaid Services (CMS).11 Furthermore, NIS was found to have a more comprehensive demographic capture when compared to a large multistate EHR dataset in more than 25 diagnosis groups, including cardiovascular disorders. $\underline{12}$

\section{Study Design and Population}


A retrospective observational analysis using the NIS database from 2004 to 2014 was performed. A total of 1,367,844 records with a primary discharge diagnosis of AMI, including ST-Elevation myocardial infarction (STEMI) and non-ST elevation myocardial infarction (NSTEMI), were extracted from the NIS datasets using the International Classification of Diseases, 9th Revision, Clinical Modification (ICD-9) codes, corresponding to a total of $6,750,878$ discharge estimates after applying the discharge weight. ICD-9 and Clinical Classification Software (CCS) codes used to identify patient characteristics, outcomes and comorbidities are listed in Supplementary Table 1. The cohort was stratified according to the presence or absence of leukemia, which was also identified using the relevant ICD-9 codes, into 2 groups, namely 'no leukemia' and 'leukemia'. The leukemia group was further stratified according to diagnosis into 4 subgroups (AML, CML, ALL and CLL) for sub-analysis purposes. All patients who were $\geq 18$ years of age were included. Records with missing age, gender, admission or discharge date, length of stay and mortality were excluded from the analysis. A flow diagram illustrating the selection process in the present study is presented in Supplementary Figure 1.

Procedural data and clinical outcomes other than in-hospital mortality, length of stay and total charges were extracted using the relevant ICD-9 and CCS diagnosis and procedure codes listed in Supplementary Table 1; bleeding, cardiac complications, use of assist device or intra-aortic balloon pump (IABP), shock during hospitalization and the receipt of coronary angiography and revascularization (PCI and CABG).

\section{Outcomes}

The co-primary outcomes were in-hospital rates of major acute cardiovascular and cerebrovascular events (MACCE), all-cause mortality, acute stroke/TIA and all-cause bleeding. MACCE was defined as a composite of all-cause mortality, stroke and cardiac 
complications (pericardiocentesis, cardiac tamponade, hemopericardium or coronary dissection). Bleeding was defined as any post-procedural hemorrhage or haematomas, or bleeding requiring transfusion according to ICD-9 and CCS codes specified in Supplementary Table 1.

The secondary outcome was to evaluate differences in receipt of invasive management, including coronary angiography and revascularization (PCI or $\mathrm{CABG}$ ), and economic burden of a concomitant leukemia diagnosis in patients hospitalized for AMI as measured by length of stay and total hospitalization charges.

\section{Statistical Analysis}

Statistical analysis was performed using SPSS version 24 (IBM Corp, Armonk, NY). Continuous variables are presented as medians with interquartile range (IQR) and were compared using the Mann-Whitney test for differences between leukemia and non-leukemia groups and using the Kruskal-Wallis test for difference between leukemia subgroups. Categorical variables are presented as percentages and were analyzed using the chi-squared $\left(\mathrm{X}^{2}\right)$ test.

Multivariable logistic regression was used to assess 1) the impact of any leukemia on in-hospital adverse outcomes and 2) differences in adverse outcomes between leukemia subgroups in comparison to patients without leukemia. The following covariates were adjusted for in all analyses: age, sex, elective admission, weekend admission, primary expected payer, median household income, dyslipidemia, smoking status, previous AMI, previous coronary artery bypass grafting (CABG), history of ischemic heart disease (IHD), previous percutaneous coronary intervention (PCI), previous cerebrovascular accident (CVA), thrombocytopenia and family history of coronary artery disease (CAD), use of assist device or intra-aortic balloon 


\section{Results}

A total of $6,968,777$ hospitalizations for AMI were recorded in the United States between 2004 and 2014. After excluding all discharges with missing data on covariates or outcomes, as well as cases with more than one leukemia diagnosis, a total of $6,750,878$ patients were included in the final analysis (Supplementary Figure 1). The total numbers of exclusions accounts for approximately $3 \%$ of the original dataset.

The patient characteristics of the study population are presented according to the presence or absence of leukemia in Table 1. Patients with a current history of leukemia diagnosis comprised $0.3 \%(n=21,694)$ of the study cohort. AMI patients with a leukemia diagnosis were almost a decade older ( 77 vs. 68 years), more likely to be male $(65.2 \%$ vs. $60.2 \%)$ and of White ethnic background (87.8\% vs. $77.1 \%)$. Furthermore, patients with leukemia were less likely to be diagnosed with STEMI during admission (24.8\% vs. $35.1 \%$ ) 
and more likely to have abnormal hematological parameters including thrombocytopenia (14.0\% vs. $3.1 \%)$, coagulopathy (17.4\% vs. $4.2 \%)$ and deficiency anemias (25.4\% vs. $14.6 \%)$.

The leukemia group was further stratified according to diagnosis into four subgroups; AML (10.5\%, n=2278), CML (15.8\%, n=3437), ALL (1.7\%, n=379) and CLL (71.9\%, $\mathrm{n}=15,600$ ), the latter being the most common subtype. Supplementary Table 2 shows the patient characteristics of each of the leukemia subgroups. Several key differences were seen across the leukemia groups. There was more than a decade difference in the median age range between groups (65-79 years) with ALL patients being predominantly younger ( 65 years) and CLL patients being older ( 79 years). The percentage of males ranged from $62.6 \%$ to $73.6 \%$ with a higher prevalence of men in the acute leukemia groups than in the chronic leukemia groups (Males \%: CML: 62.6\% and CLL 64.4\% vs. AML 72.8\% and ALL 73.6\%). The highest rate of thrombocytopenia was observed in the AML group (25.1\%) Furthermore, ALL patients were less likely to be of 'White' ethnic background compared to all other subgroups (78\%).

\section{Management strategy}

Patients with leukemia were less likely to receive coronary angiography (48.5\% vs. $64.5 \%$ ) or any revascularization (PCI: $28.2 \%$ vs. $42.9 \%$; CABG: $6.9 \%$ vs. $8.9 \%$ ) (Table 2 , Figure 1). Within the leukemia subgroups, AML patients were the least likely to receive coronary angiography $(33.4 \%)$, PCI (20.2\%) or CABG $(3.2 \%)$. (Table 3$)$

\section{In-hospital Mortality, MACCE and Stroke}

Patients with leukemia experienced significantly higher rates of in-hospital MACCE $(11.8 \%$ vs. $7.8 \%)$ and mortality $(10.3 \%$ vs. $5.8 \%)$ in comparison to those without leukemia (Table 2, Figure 2). However, the rates of in-hospital stroke and cardiac complications were lower in patients with leukemia (stroke: $1.4 \%$ vs. $1.7 \%$; cardiac complications: $0.5 \%$ vs. $0.7 \%$, 
respectively). Multivariable analysis was performed to determine the adjusted effect of leukemia on in-hospital outcomes (Tables 5). The presence of leukemia was associated with a $25 \%$ increase in odds of MACCE (OR $1.26[1.20,1.31])$ and $40 \%$ increase in odds of mortality (OR $1.43[1.37,1.50])$. In contrast, the presence of leukemia was associated with lower odds of in-hospital stroke (OR $0.71[0.64,0.80])$.

In subgroup analysis according to leukemia subtype, the highest rates of in-hospital MACCE and mortality were found in patients with AML (21.1\% and 20.2\% respectively), while the lowest rates of both events were found in ALL (MACCE: 8.5\%; mortality: 7.3\%) (Figure 2). Patients with CML had the highest rates of in-hospital stroke (2.0\%) and cardiac complications $(1.0 \%)$ in comparison to all other subgroups.

In comparison to patients without leukemia, patients with AML were approximately at 3-fold increased odds of MACCE (OR 2.81 [2.51, 3.13]) and 4-fold increased odds of mortality (OR $3.75[3.34,4.22]$ ) (Supplementary Table 3, Figure 3). Patients with ALL were also at increased odds of mortality (OR $1.73[1.14,2.63])$. The effect of lymphoid leukemias on MACCE was not found to be statistically significant (ALL: OR 1.32 [0.90, 1.94]; CLL: OR $1.06[0.99,1.11])$. Patients with AML and CLL were associated with significantly reduced odds of in-hospital stroke (OR $0.47[0.30,0.73]$ and OR $0.68[0.59,0.78]$, respectively) whereas no difference in stroke was found between ALL and CML groups (OR 0.78 [0.31, 1.99] and OR 1.04 [0.81, 1.33], respectively) and those without leukemia. (Supplementary Table 3, Figure 3).

\section{Bleeding}

Patients with leukemia experienced higher rates of in-hospital bleeding compared to those without leukemia (5.6\% vs. 5.3\%; Table 2, Figure 2). However, in multivariate analysis the adjusted effect of leukemia was a reduction in odds of bleeding (OR 0.86 [0.81, 0.92]). Within the subgroups of leukemia, patients with CML had the highest rates of bleeding (7.2 
\%) while patients with AML experienced the lowest rates of bleeding (4.4\%) (Table 3, Figure 2). In comparison to patients without leukemia, patients with CML were at $20 \%$ increased odds of bleeding (adjusted OR $1.20[1.05,1.37]$ ) while all other subgroups were associated with reduced odds of bleeding (Supplementary Table 3, Figure 3).

\section{Length of stay and hospitalization charges}

The median length of hospital stay of leukemia patients was marginally longer than in patients without leukemia ( 4 vs. 3 days). However, there was no difference in length of stay between the leukemia subgroups ( 4 days in all subgroups, $p=0.76$ ) (Table 3 ). While the total charge of hospitalization was less in patients with leukemia (median total charges: $\$ 39,387$ vs. $\$ 43,155$, Table 2$)$, there was a notable variation in median costs between leukemia subgroups. Patients with ALL represented the most expensive median cost of hospitalization amongst subgroups $(\$ 47,674)$, followed by CML $(\$ 42,302)$, CLL $(\$ 39,387)$ and AML $(\$ 36,516)$ (Table 3).

\section{Discussion}

Our analysis of a national cohort of over 21,000 patients with leukemia presenting with an AMI suggests that patients with leukemia are older, have more comorbidities and are less likely to receive either diagnostic cardiac catheterization or coronary revascularization compared to patients without leukemia. We also observe that patients with leukemia are a heterogenous group of patients with different risk factor profiles and clinical outcomes following presentation with AMI, with the chronic forms of leukemia (CLL and CML) being most commonly encountered and accounting for $85 \%$ of cases. Finally, we show, that whilst all leukemia is associated with a poorer prognosis, patients with AML have the poorest prognosis, with a 4-fold and 3-fold increased odds mortality and MACCE, respectively, whilst patients with CML are at the highest risk of major bleeding complications. 
With active malignancy being an exclusion criterion in most AMI trials, clinicians are faced with a lack of data to guide their decision-making. Given the numerous unknowns in the platelet and coagulation cascade of these patients with hematologic malignancies, there may be hesitation to simply extrapolate standard AMI treatment protocols in these patients. Use of anticoagulants, antiplatelets, and invasive strategies for AMI carries the obvious risk of bleeding complications but whether that risk outweighs the benefit in leukemia patients is unknown, nor is it known if certain subtypes of leukemia respond differently. This study helps to understand the differences in AMI management, outcomes, and complications in patients with leukemia compared to those without and between the subtypes of leukemia. Patients with leukemia were older, with a mean age difference of about a decade, with older age being an already known adverse prognostic factor in AML. 13 We observed differences in type of ACS presentation in patients with leukemia, with STEMI occurring less commonly. This may be due to greater prevalence of type 2 AMIs secondary to supply / demand mismatch in this cohort, $\underline{14}$ related to their disease-specific comorbidities (anemia, sepsis, dehydration, drug toxicity, etc.). Patients with leukemia also had significantly higher prevalence of thrombocytopenia $(>10 \%$ prevalence in all types of leukemia compared to $3 \%$ in patients without leukemia) with the highest rates (one-quarter) in those with AML. Thrombocytopenia may act as deterrent to undertaking coronary angiography and subsequent revascularization in patients with AMI and leukemia, given concerns regarding risk of periprocedural bleeding and ability to tolerate antiplatelet agents following PCI. However, reassuring data from large cancer centers in the US suggests that the use of antiplatelets is safe and improves survival in cancer patients with MI and thrombocytopenia, although latest data on newer P2Y12 inhibitors is lacking. 15,16 Recent data also suggests that if transradial vascular access is performed, invasive coronary angiography and PCI can be performed safely in cancer patients with chronic thrombocytopenia. 17 Coagulopathy was more prevalent in patients with leukemia $(17.4 \%$ vs 
4.2\%), particularly in patients with AML (29\%). This may relate to disseminated intravascular coagulation (DIC) secondary to sepsis, hepatic injury, hepatic toxicity or due to a specific type of AML (acute promyelocytic leukemia (APL) $\underline{18}$ whose incidence has been reported as 13\% of new AML cases 19 . Renal impairment was more common in patients with leukemia, again reflecting an older population with more comorbidities.

Interestingly, when looking at all-cause bleeding, there was a statistically significant difference towards increased bleeding in patients with leukemia, but the difference was only $0.3 \%$. This may be confounded by the use of less aggressive antithrombotic regimes in this patient group, although the NIS does not capture pharmacological therapy.

We have observed significant differences in the prognosis associated with different types of leukemia following admission with AMI. Patients with AML had the worst outcomes, with an independent 3-fold increase in MACCE and a 4-fold increase in mortality. AML patients also were least likely to undergo invasive management, with less than one third undergoing diagnostic coronary angiography and only $20 \%$ treated with PCI. This may relate to the higher risk profile of these patients, particularly given their elevated bleeding risk, but may also relate to the fact that these patients have been excluded from all major trials that have shown benefit of invasive strategies in the treatment of ACS. Further data is needed to assess whether invasive management might decrease mortality in patients with leukemia presenting with an AMI, particularly in AML. Patients with CML had the highest risk of bleeding complications $(1.20[1.05,1.37 ; \mathrm{p}<0.007])$, which may also be confounded by the age given patients with CML have a higher average age compared to patients without leukemia (74 vs 68 years old). With the advent of tyrosine kinase inhibitors (TKI), the therapeutic options for CML patients have expanded significantly.20 Dasatinib, a widely used TKI in CML, has been reported to cause increase in risk of bleeding, 21 through a mechanism proposed to be mediated by platelet dysfunction 22 . Part of this increased risk of bleeding in our study could be related 
to combined treatment of antiplatelet and anticoagulants used for the management of AMI and concomitant use of some TKI (imatinib and dasatinib) 22 for CML. The risk versus benefit of continuing TKI treatment while starting antithrombotic agents in the AMI setting should be carefully assessed and individualized in these patients.

ALL was relatively rare in this cohort $(n=379)$, only accounting for $1.7 \%$ of leukemia cases, hence the data around outcomes and treatment in ALL is limited. Once the differences in the clinical characteristics were adjusted for these patients were found to have a $70 \%$ increased risk of in-hospital mortality. The most common subtype of leukemia in our study was CLL, in keeping with it being the most prevalent leukemia in adults in the western hemisphere.23 The majority of CLL patients are diagnosed incidentally and generally have an indolent course initially. $\underline{24}$ Patients with CLL were on average a decade older than patients without leukemia and had a modest increase in the risk of in-hospital mortality (18\%).

When managing high-risk groups such as those with leukemia, clinicians need to consider both the ischemic and bleeding risks associated with AMI and leukemia, respectively. 25 Decisions around the treatment of AMI should be made by an interdisciplinary team that includes oncology and cardiology as well as other consultative services to balance the risks versus the benefits. A cautious approach that includes adoption of careful bleeding avoidance strategies should be instituted rather than automatic deferment of the invasive strategies in patients presenting with AMI. The use of micro-puncture techniques for vascular access, radial access, reduced dosing of anticoagulants in patients with platelet counts $<30,000 \mathrm{~mm} 3$, introduction of thinner strut and polymer free platforms and the use of intravascular imaging (intravascular ultrasound and Optical Coherence Tomography) to optimize PCI results are some of the strategies that have enabled the interventional cardio-oncology programs to have acceptable rates of complications in this challenging group of patients. 26 


\section{Limitations}

First, the NIS is an administrative dataset that is susceptible to coding inaccuracies. Although the identification of ACS and leukemia diagnoses as well as other comorbidities was based on the use of administrative codes, ICD-9 codes have been previously validated for the purposes of cardiovascular research. 27 Secondly, since the NIS dataset does not capture pharmacotherapy, we were unable to determine differences in the prescription of antithrombotic therapy between the study groups. Similarly, NIS does not capture lab values, hence the platelet counts, and the degree or type of coagulopathy was unknown. Nevertheless, we have adjusted for the presence of thrombocytopenia and coagulopathy in our analysis. Additionally, the reduced rates of PCI in those with leukemia may be explained by lack of obstructive coronary artery disease in those with a Type 2 AMI. Third, the NIS database does not capture the cause of mortality and, therefore, we were unable to determine how much of the observed mortality is attributable to cardiovascular causes. Finally, classifications regarding the severity and duration of each subtype of leukemia was not possible given limitations of ICD-9 codes.

\section{Conclusion}

A concomitant leukemia diagnosis in patients presenting with AMI is associated with an overall increase in MACCE and mortality, which further differs according to the subtype of leukemia. Patients with leukemia are generally older, have more comorbidities, and have higher prevalence of coagulopathies and thrombocytopenia, which may deter cardiologists from pursuing invasive therapies and may limit the use of antithrombotic agents. Still for the most part, we have observed that the in-hospital bleeding risk is low, except in CML. AML has the highest risk of mortality with the lowest receipt of invasive strategies / revascularization. Clinical management of this complex group of patients should involve a multi-disciplinary 
team including oncologists and cardiologists. To help improve the care of leukemia patients, further studies are needed in order to better assess the risk versus benefit of more aggressive management of AMI.

\section{Conflicts}

The authors have no disclosures and no relationships with the pharmaceutical industry.

\section{Funding}

There are no funding disclosures for any of the co-authors.

\section{Authorship Statement}

MAM designed the study. MOM extracted and analyzed the data and drafted the initial manuscript. All other co-authors provided critical editing and review of the scientific content of the manuscript, including advice regarding the statistical content. The manuscript has neither been published nor is currently under consideration for publication by any other journal. All authors have approved the final version of the manuscript.

\section{References}

1. Noone A, Howlader N, Krapcho M, et al. SEER Cancer Statistics Review, 1975-2015. National Cancer Institute. Bethesda, MD, https://seer.cancer.gov/csr/1975 2015/, based on November 2017 SEER data submission, posted to the SEER web site, April 2018.;2017.

2. UK CR. Leukaemia (all subtypes combined) incidence statistics. 2015; https://www.cancerresearchuk.org/health-professional/cancer-statistics/statistics-bycancer-type/leukaemia/incidence\#theading-Zero. Accessed 30/07/2018, 2018.

3. Guzmán-Uribe P, Vargas-Ruíz ÁG. Thrombosis in Leukemia: Incidence, Causes, and Practical Management. Current Oncology Reports. 2015;17(5):19.

4. Beinart G, Damon L. Thrombosis associated with 1-asparaginase therapy and low fibrinogen levels in adult acute lymphoblastic leukemia. American Journal of Hematology. 2004;77(4):331-335. 
5. Cargill RI, Boyter AC, Lipworth BJ. Reversible myocardial ischaemia following vincristine containing chemotherapy. Respir Med. 1994;88(9):709-710.

6. Potts J, Mohamed MO, Lopez Mattei JC, et al. Percutaneous coronary intervention and in-hospital outcomes in patients with leukemia: a nationwide analysis. Catheter Cardiovasc Interv. 2019.

7. István B, Erzsébet L, Johanna S-K, Szilárd B, Szende J, István B. Acute Coronary Syndromes in Patients with Hematological Disorders. Journal Of Cardiovascular Emergencies. 2016;2(4):159-168.

8. Cohen Y, Amir G, Da'as N, Gillis S, Rund D, Polliack A. Acute myocardial infarction as the presenting symptom of acute myeloblastic leukemia with extreme hyperleukocytosis. American journal of hematology. 2002;71(1):47-49.

9. Saviola A, Luppi M, Potenza L, et al. Myocardial ischemia in a patient with acute lymphoblastic leukemia during L-asparaginase therapy. European journal of haematology. 2004;72(1):71-72.

10. HCUP National Inpatient Sample (NIS). Healthcare Cost and Utilization Project (HCUP), Agency for Healthcare Research and Quality, Rockville, MD. 2012; www.hcup-us.ahrq.gov/nisoverview.jsp

11. Barrett M WE, Whalen D. . HCUP Nationwide Inpatient Sample (NIS) Comparison Report. HCUP Methods Series Report. 2007(2010-03).

12. DeShazo JP, Hoffman MA. A comparison of a multistate inpatient EHR database to the HCUP Nationwide Inpatient Sample. BMC Health Serv Res. 2015;15:384.

13. Appelbaum FR, Gundacker H, Head DR, et al. Age and acute myeloid leukemia. Blood. 2006;107(9):3481-3485.

14. Mihatov N, Januzzi JL, Gaggin HK. Type 2 myocardial infarction due to supplydemand mismatch. Trends in Cardiovascular Medicine. 2017;27(6):408-417.

15. Yusuf SW, Daraban N, Abbasi N, Lei X, Durand JB, Daher IN. Treatment and outcomes of acute coronary syndrome in the cancer population. Clinical cardiology. 2012;35(7):443-450.

16. Feher A, Kampaktsis PN, Parameswaran R, Stein EM, Steingart R, Gupta D. Aspirin Is Associated with Improved Survival in Severely Thrombocytopenic Cancer Patients with Acute Myocardial Infarction. The oncologist. 2017;22(2):213-221.

17. Iliescu C, Balanescu DV, Donisan T, et al. Safety of Diagnostic and Therapeutic Cardiac Catheterization in Cancer Patients With Acute Coronary Syndrome and Chronic Thrombocytopenia. The American journal of cardiology. 2018;122(9):14651470.

18. Mantha S, Tallman MS, Soff GA. What's new in the pathogenesis of the coagulopathy in acute promyelocytic leukemia? Current opinion in hematology. 2016;23(2):121-126.

19. Grimwade D, Hills RK, Moorman AV, et al. Refinement of cytogenetic classification in acute myeloid leukemia: determination of prognostic significance of rare recurring chromosomal abnormalities among 5876 younger adult patients treated in the United Kingdom Medical Research Council trials. Blood. 2010;116(3):354-365.

20. O'Brien SG, Guilhot F, Larson RA, et al. Imatinib compared with interferon and lowdose cytarabine for newly diagnosed chronic-phase chronic myeloid leukemia. The New England journal of medicine. 2003;348(11):994-1004.

21. Quintas-Cardama A, Kantarjian H, Ravandi F, et al. Bleeding diathesis in patients with chronic myelogenous leukemia receiving dasatinib therapy. Cancer. 2009;115(11):2482-2490.

22. Quintas-Cardama A, Han X, Kantarjian H, Cortes J. Tyrosine kinase inhibitor-induced platelet dysfunction in patients with chronic myeloid leukemia. Blood. 2009;114(2):261-263. 
23. Kipps TJ, Stevenson FK, Wu CJ, et al. Chronic lymphocytic leukaemia. Nature reviews Disease primers. 2017;3:16096.

24. Burger JA, O'Brien S. Evolution of CLL treatment - from chemoimmunotherapy to targeted and individualized therapy. Nature reviews Clinical oncology. 2018;15(8):510-527.

25. Mohamed MO, Kinnaird T, Anderson R, et al. Combinations of bleeding and ischemic risk and their association with clinical outcomes in acute coronary syndrome. International Journal of Cardiology. 2019;290:7-14.

26. Iliescu CA, Grines CL, Herrmann J, et al. SCAI Expert consensus statement: Evaluation, management, and special considerations of cardio-oncology patients in the cardiac catheterization laboratory (endorsed by the cardiological society of india, and sociedad Latino Americana de Cardiologia intervencionista). Catheterization and cardiovascular interventions : official journal of the Society for Cardiac Angiography \& Interventions. 2016;87(5):E202-223.

27. Birman-Deych E, Waterman AD, Yan Y, Nilasena DS, Radford MJ, Gage BF. Accuracy of ICD-9-CM Codes for Identifying Cardiovascular and Stroke Risk Factors. Medical Care. 2005;43(5).

\section{Figures and Legends:}

Figure 1. Rate of revascularization according to subtype of leukemia

Caption: CA: Coronary angiography; PCI: Percutaneous coronary intervention; CABG:

Coronary artery bypass grafting

\section{Figure 2. Crude rates of adverse events in study groups}

\section{Figure 3. Odds ratios and $95 \%$ confidence intervals (CI) of adverse events according to subtype of leukemia}

Caption: MACCE: major adverse cardiovascular and cerebrovascular events: composite of mortality, stroke and cardiac complications; *non-significant; $\uparrow \mathrm{p} \leq 0.01 ; \ddagger \mathrm{p} \leq 0.001$; *reference group; $\S$ nonsignificant; $\uparrow \mathrm{p} \leq 0.01 ; \uparrow \mathrm{p} \leq 0.001$ 
Table 1. Patient characteristics of study groups

\begin{tabular}{|c|c|c|c|c|}
\hline Variable/Group (\%) & $\begin{array}{c}\text { No Leukemia } \\
(99.7)\end{array}$ & $\begin{array}{c}\text { Leukemia } \\
(0.3)\end{array}$ & Total & p-value \\
\hline Number of weighted discharges & 6729184 & 21694 & 6750878 & $<0.001$ \\
\hline Age (years), median (IQR) & $68(57,79)$ & $77(69,84)$ & $68(57,79)$ & $<0.001$ \\
\hline Males, \% & 60.2 & 65.2 & 60.2 & $<0.001$ \\
\hline Ethnicity, \% & & & & $<0.001$ \\
\hline White & 77.1 & 87.8 & 77.1 & \\
\hline Black & 9.7 & 5.2 & 9.7 & \\
\hline Hispanic & 7.4 & 3.8 & 7.3 & \\
\hline Asian/Pacific Islander & 2.2 & 0.9 & 2.2 & \\
\hline Native American & 0.5 & 0.2 & 0.5 & \\
\hline Other & 3.1 & 2.1 & 3.1 & \\
\hline STEMI, \% & 35.1 & 24.8 & 35.1 & \\
\hline Elective Admission, \% & 7.1 & 6.7 & 7.1 & $<0.001$ \\
\hline Weekend admission, \% & 25.9 & 25.2 & 25.9 & $<0.001$ \\
\hline Primary expected payer, $\%$ & & & & $<0.001$ \\
\hline Medicare & 57.3 & 80.5 & 57.4 & \\
\hline Medicaid & 5.9 & 1.4 & 5.9 & \\
\hline Private Insurance & 27.7 & 15.0 & 27.7 & \\
\hline Self-pay & 5.8 & 1.1 & 5.7 & \\
\hline No charge & 0.6 & 0.1 & 0.6 & \\
\hline other & 2.7 & 1.9 & 2.7 & \\
\hline $\begin{array}{l}\text { Median Household Income } \\
\text { (percentile), \% }\end{array}$ & & & & $<0.001$ \\
\hline $0-25^{\text {th }}$ & 28.6 & 23.5 & 28.5 & \\
\hline $26-50^{\text {th }}$ & 27.4 & 28.2 & 27.4 & \\
\hline $51-75^{\text {th }}$ & 23.7 & 24.6 & 23.7 & \\
\hline $76-100^{\text {th }}$ & 20.4 & 23.7 & 20.4 & \\
\hline \multicolumn{5}{|l|}{ Comorbidities, $\%$} \\
\hline Dyslipidemia & 54.2 & 46.0 & 54.2 & $<0.001$ \\
\hline Thrombocytopenia & 3.1 & 14.0 & 3.1 & $<0.001$ \\
\hline Smoking & 34.0 & 21.9 & 34.0 & $<0.001$ \\
\hline Previous AMI & 10.2 & 10.4 & 10.2 & $<0.001$ \\
\hline History of IHD & 76.7 & 72.0 & 76.7 & $<0.001$ \\
\hline Previous PCI & 11.4 & 12.3 & 11.4 & $<0.001$ \\
\hline Previous CABG & 7.5 & 10.2 & 7.5 & $<0.001$ \\
\hline Previous CVA & 3.8 & 4.3 & 3.8 & $<0.001$ \\
\hline Family history of CAD & 7.8 & 3.8 & 7.8 & $<0.001$ \\
\hline AIDS & 0.1 & 0.0 & 0.1 & $<0.001$ \\
\hline Alcohol abuse & 2.8 & 1.2 & 2.8 & $<0.001$ \\
\hline Deficiency anemias & 14.6 & 25.4 & 14.6 & $<0.001$ \\
\hline Chronic Blood loss anemia & 1.1 & 1.1 & 1.1 & $<0.001$ \\
\hline $\begin{array}{l}\text { RA/collagen vascular } \\
\text { diseases }\end{array}$ & 2.1 & 2.3 & 2.1 & $<0.001$ \\
\hline Congestive heart failure & 0.9 & 1.5 & 0.9 & $<0.001$ \\
\hline Chronic pulmonary disease & 20.6 & 23.2 & 20.6 & $<0.001$ \\
\hline Coagulopathy & 4.2 & 17.4 & 4.3 & $<0.001$ \\
\hline
\end{tabular}




\begin{tabular}{|c|c|c|c|c|}
\hline Variable/Group (\%) & $\begin{array}{c}\text { No Leukemia } \\
(99.7)\end{array}$ & $\begin{array}{l}\text { Leukemia } \\
(0.3)\end{array}$ & Total & p-value \\
\hline Depression & 6.3 & 6.6 & 6.3 & $<0.001$ \\
\hline Diabetes & 28.0 & 27.1 & 28.0 & $<0.001$ \\
\hline Diabetes with complications & 6.0 & 5.7 & 6.0 & $<0.001$ \\
\hline Drug abuse & 2.0 & 0.6 & 2.0 & $<0.001$ \\
\hline Hypertension & 66.3 & 61.9 & 66.3 & 0.287 \\
\hline Hypothyroidism & 9.6 & 11.6 & 9.6 & $<0.001$ \\
\hline Liver disease & 1.2 & 1.0 & 1.2 & $<0.001$ \\
\hline Lymphomas & 0.5 & 2.5 & 0.5 & $<0.001$ \\
\hline $\begin{array}{l}\text { Fluid and electrolyte } \\
\text { disturbances }\end{array}$ & 19.0 & 23.6 & 19.1 & $<0.001$ \\
\hline Metastatic cancer & 0.9 & 0.8 & 0.9 & $<0.001$ \\
\hline Other neurological disorders & 5.8 & 5.6 & 5.8 & $<0.001$ \\
\hline Obesity & 11.6 & 6.1 & 11.6 & $<0.001$ \\
\hline Paralysis & 1.6 & 1.3 & 1.6 & $<0.001$ \\
\hline Peripheral vascular disease & 10.8 & 11.2 & 10.8 & $<0.001$ \\
\hline Psychoses & 2.0 & 1.5 & 2.0 & $<0.001$ \\
\hline Pulmonary circulation disorder & 0.1 & 0.2 & 0.1 & $<0.001$ \\
\hline Renal failure (chronic) & 16.4 & 22.8 & 16.4 & $<0.001$ \\
\hline Solid tumor without metastases & 1.4 & 2.7 & 1.4 & $<0.001$ \\
\hline Peptic ulcer disease & 0.0 & 0.1 & 0.0 & 0.002 \\
\hline Valvular heart disease & 0.3 & 0.5 & 0.3 & $<0.001$ \\
\hline Weight loss & 2.1 & 3.0 & 2.1 & $<0.001$ \\
\hline Hospital bed size, $\%$ & +2 & & & $<0.001$ \\
\hline Small & 10.4 & 11.1 & 10.4 & \\
\hline Medium & 24.3 & 23.6 & 24.3 & \\
\hline Large & 65.3 & 65.3 & 65.3 & \\
\hline Hospital Region, \% & & 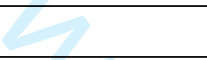 & & $<0.001$ \\
\hline Northeast & 19.5 & 22.9 & 19.5 & \\
\hline Midwest & 23.3 & 24.7 & 23.3 & \\
\hline South & 39.9 & 35.2 & 39.9 & \\
\hline West & 17.3 & 17.2 & 17.3 & \\
\hline Location/ Teaching status, \% & & & & $<0.001$ \\
\hline Rural & 10.5 & 11.9 & 10.5 & \\
\hline Urban non-teaching & 41.9 & 39.9 & 41.8 & \\
\hline Urban- teaching & 47.6 & 48.2 & 47.6 & \\
\hline
\end{tabular}

AMI: acute myocardial infarction; CABG: coronary artery bypass graft; CAD: coronary artery disease; CVA: cerebrovascular accident (stroke or transient ischemic attack); IHD: ischemic heart disease; IQR: interquartile range; STEMI: ST-elevation myocardial infarction PCI: percutaneous coronary intervention; 
Table 2. In-hospital management strategies and clinical outcomes of study groups

\begin{tabular}{lcccc}
\hline $\begin{array}{l}\text { Variable/Group (\% of } \\
\text { cohort) }\end{array}$ & $\begin{array}{c}\text { No Leukemia } \\
\mathbf{( 9 9 . 7 )}\end{array}$ & $\begin{array}{c}\text { Leukemia } \\
\mathbf{( 0 . 3 )}\end{array}$ & Total & p-value \\
\hline MACCE, \% & 7.8 & 11.8 & 7.8 & $<0.001$ \\
\hline Cardiac complications, \% & 0.7 & 0.5 & 0.7 & $<0.001$ \\
\hline Stroke, \% & 1.7 & 1.4 & 1.7 & $<0.001$ \\
\hline All-cause mortality, \% & 5.8 & 10.3 & 5.8 & $<0.001$ \\
\hline All-cause bleeding, \% & 5.3 & 5.6 & 5.3 & $<0.001$ \\
\hline $\begin{array}{l}\text { Use of assist device or } \\
\text { IABP, \% }\end{array}$ & 4.9 & 3.3 & 4.9 & $<0.001$ \\
\hline Shock, \% & 4.9 & 4.6 & 4.9 & $<0.001$ \\
\hline $\begin{array}{l}\text { Receipt of coronary } \\
\text { angiography, \% }\end{array}$ & 64.5 & 48.5 & 64.5 & $<0.001$ \\
\hline Receipt of PCI, \% & 42.9 & 28.2 & 42.9 & $<0.001$ \\
\hline Receipt of CABG, \% & 8.9 & 6.9 & 8.9 & $<0.001$ \\
\hline $\begin{array}{l}\text { Length of stay (days), } \\
\text { median (IQR) }\end{array}$ & $3(2,6)$ & $4(2,7)$ & $3(2,6)$ & $<0.001$ \\
\hline $\begin{array}{l}\text { Total charge (\$), median } \\
\text { (IQR) }\end{array}$ & 43155 & 39387 & 43142 & $<0.001$ \\
\hline CABG: corary & $(22417,75161)$ & $(19383,72990)$ & $(22407,75156)$ & \\
\hline
\end{tabular}

CABG: coronary artery bypass grafting; MACCE: major adverse cardiovascular and cerebrovascular events: composite of mortality, stroke and cardiac complications; PCI: percutaneous coronary intervention 
Table 3. In-hospital management strategies and clinical outcomes according to leukemia subtype

\begin{tabular}{|c|c|c|c|c|c|}
\hline $\begin{array}{l}\text { Variable/Outcome } \\
\text { (\% of all leukemias) }\end{array}$ & $\begin{array}{l}\text { AML } \\
(\mathbf{1 0 . 5})\end{array}$ & $\begin{array}{l}\text { CML } \\
(\mathbf{1 5 . 8})\end{array}$ & $\begin{array}{l}\text { ALL } \\
(1.7)\end{array}$ & $\begin{array}{l}\text { CLL } \\
(71.9)\end{array}$ & p-value \\
\hline МАССЕ, \% & 21.1 & 11.0 & 8.5 & 10.7 & $<0.001$ \\
\hline $\begin{array}{l}\text { Cardiac complications, } \\
\%\end{array}$ & 0.2 & 1.0 & 0.0 & 0.4 & $<0.001$ \\
\hline Stroke, $\%$ & 0.9 & 2.0 & 1.1 & 1.4 & \\
\hline All-cause mortality, \% & 20.2 & 8.4 & 7.3 & 9.3 & $<0.001$ \\
\hline All-cause bleeding, \% & 4.4 & 7.2 & 5.1 & 5.4 & $<0.001$ \\
\hline $\begin{array}{l}\text { Use of assist device or } \\
\text { IABP, \% }\end{array}$ & 1.9 & 2.7 & 3.7 & 3.6 & $<0.001$ \\
\hline Shock, \% & 6.8 & 4.4 & 5.2 & 4.3 & $<0.001$ \\
\hline $\begin{array}{l}\text { Receipt of coronary } \\
\text { angiography, \% }\end{array}$ & 33.4 & 51.6 & 57.9 & 49.8 & $<0.001$ \\
\hline Receipt of PCI, \% & 20.2 & 28.5 & 32.6 & 29.3 & $<0.001$ \\
\hline Receipt of CABG, \% & 3.2 & 6.5 & 6.2 & 7.5 & $<0.001$ \\
\hline $\begin{array}{l}\text { Length of stay (days), } \\
\text { median (IQR) }\end{array}$ & $4(2,7)$ & $4(2,7)$ & $4(2,8)$ & $4(2,7)$ & 0.760 \\
\hline $\begin{array}{l}\text { Total charge (\$), median } \\
\text { (IQR) }\end{array}$ & $\begin{array}{c}36516 \\
(18351,68813) \\
\end{array}$ & $\begin{array}{c}42302 \\
(21236,71826) \\
\end{array}$ & $\begin{array}{c}47674 \\
(20348,93569) \\
\end{array}$ & $\begin{array}{c}39387 \\
(19181,73469) \\
\end{array}$ & $<0.001$ \\
\hline
\end{tabular}

CABG: coronary artery bypass grafting; MACCE: major adverse cardiovascular and cerebrovascular events: composite of mortality, stroke and cardiac complications; PCI: percutaneous coronary intervention 


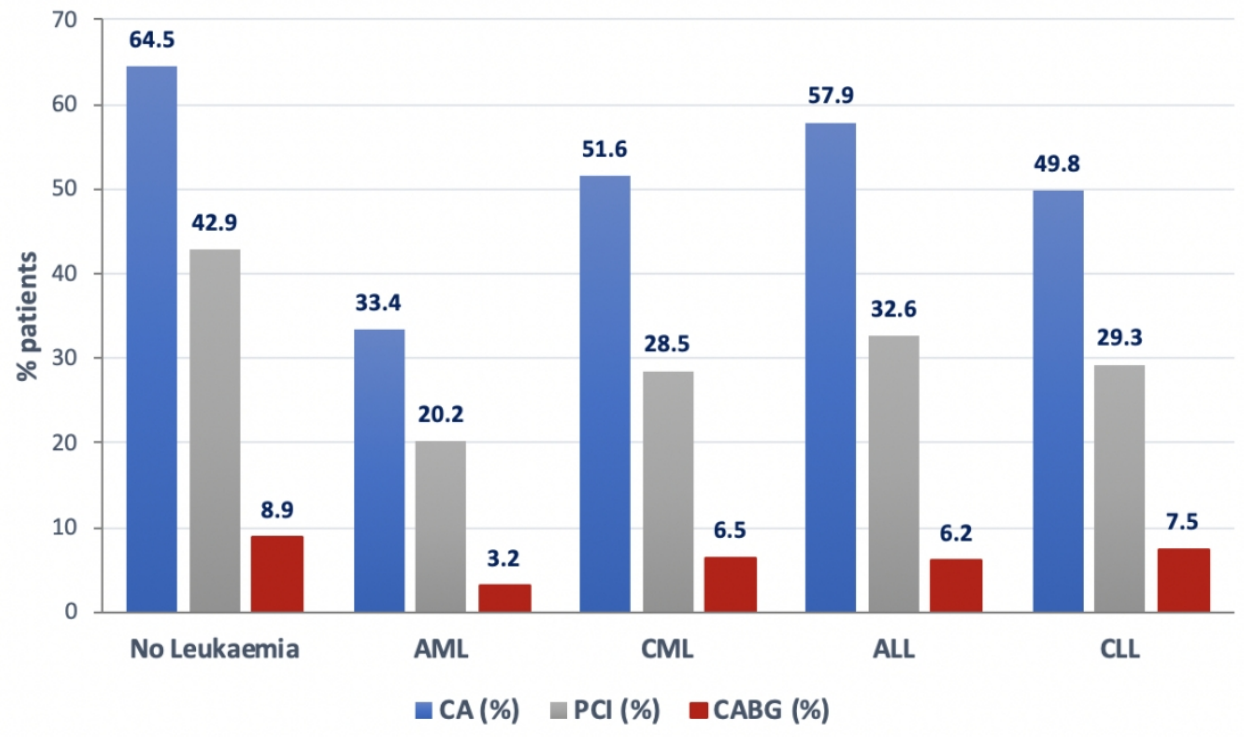

Figure 1. Rate of revascularization according to subtype of leukemia

Caption: CA: Coronary angiography; PCI: Percutaneous coronary intervention; CABG: Coronary artery bypass grafting

$104 \times 64 \mathrm{~mm}(300 \times 300 \mathrm{DPI})$ 


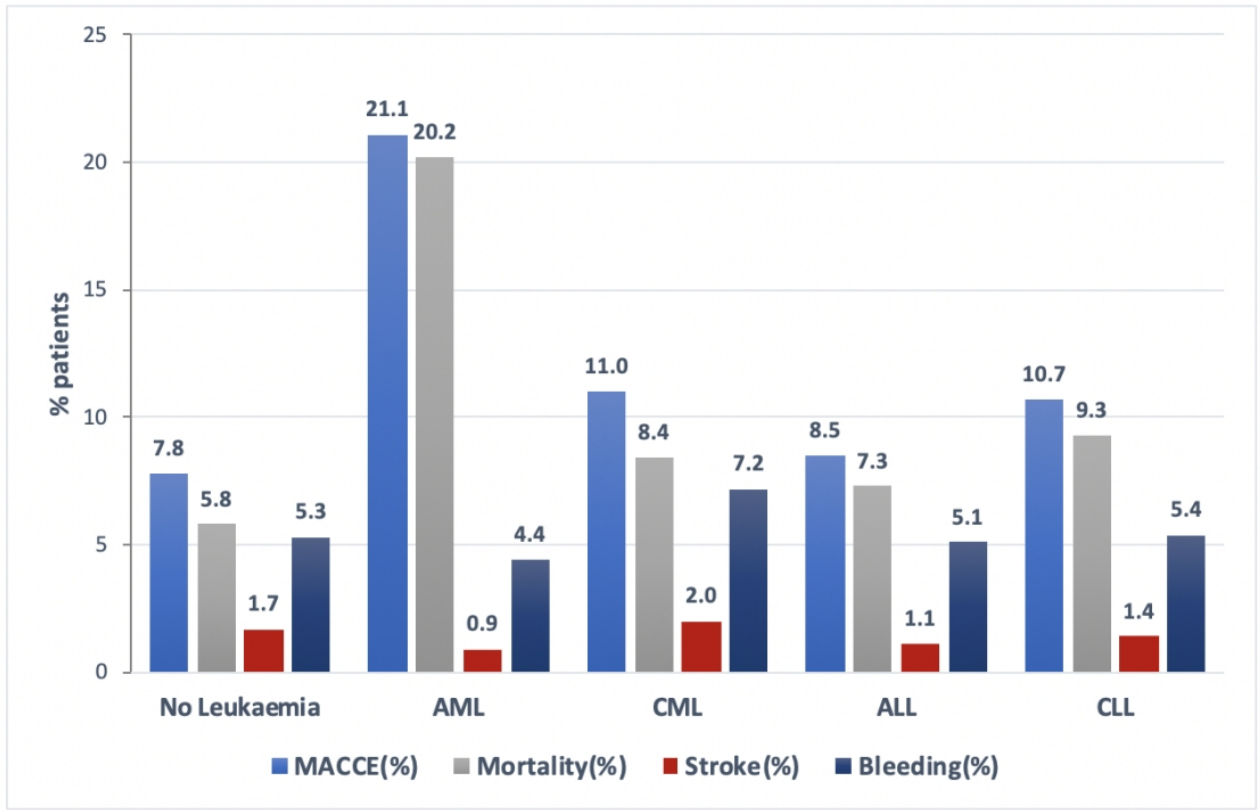

Figure 2. Crude rates of adverse events in study groups $110 \times 74 \mathrm{~mm}(300 \times 300 \mathrm{DPI})$ 
Figure 3. Odds ratios and $95 \%$ confidence intervals (CI) of adverse events according to subtype of leukemia

Caption: MACCE: major adverse cardiovascular and cerebrovascular events: composite of mortality, stroke and cardiac complications; *non-significant; $+p \leq 0.01 ; \neq p \leq 0.001 ; *$ reference group; $\S$ non-significant; $+p \leq 0.01 ; \neq p \leq 0.001$

$162 \times 97 \mathrm{~mm}(300 \times 300 \mathrm{DPI})$ 


\section{Supplementary Figure 1. Flow diagram of study design}

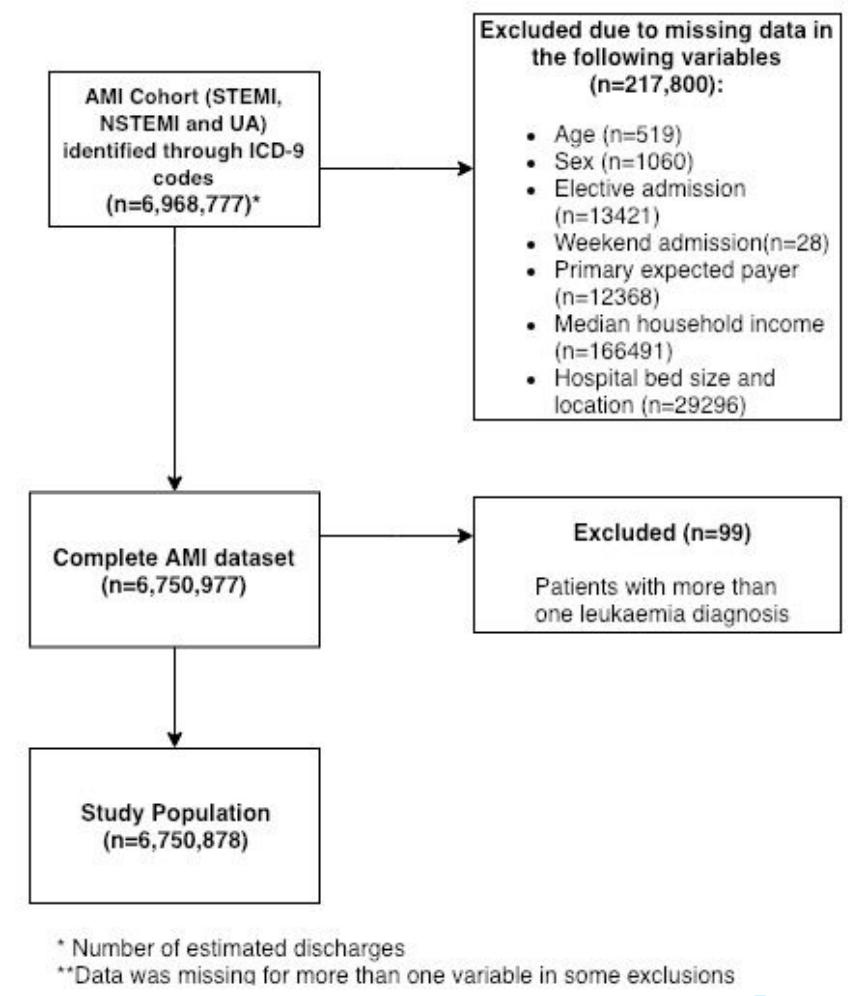

Supplementary Table 1. Search Codes

\begin{tabular}{|c|c|c|}
\hline Variable & Source & Codes \\
\hline \multicolumn{3}{|l|}{ Diagnoses } \\
\hline STEMI & ICD-9 & $\begin{array}{l}410.0 x, 410.1 x, 410.2 x, 410.3 x \\
410.4 x, 410.5 x, 410.6 x, 410.8 x\end{array}$ \\
\hline NSTEMI & ICD-9 & $410.70,410.71,410.72$ \\
\hline AML & ICD-9 & $205.00-02$ \\
\hline CML & ICD-9 & $205.10-12$ \\
\hline ALL & ICD-9 & $204.00-02$ \\
\hline CLL & ICD-9 & $204.10-12$ \\
\hline $\mathrm{AF}$ & ICD-9 & 427.31 \\
\hline Dyslipidemia & CCS & 53 \\
\hline Smoking Status & ICD-9 & V15.82, 305.1 \\
\hline History of IHD & ICD-9 & $414.00-07,414.2-9$ \\
\hline Previous MI & ICD-9 & 412 \\
\hline Previous PCI & ICD-9 & V45.82 \\
\hline Previous CABG & ICD-9 & V45.81 \\
\hline Family history of CAD & ICD-9 & V17.3 \\
\hline $\begin{array}{l}\text { Previous CVA (TIA and } \\
\text { Stroke) }\end{array}$ & ICD-9 & V12.54 \\
\hline $\begin{array}{l}\text { Dementia (Presenile, Senile, } \\
\text { Vascular and Alzheimer's) }\end{array}$ & ICD-9 & $\begin{array}{l}290.10-13,290.20-21,290.40- \\
43,294.10-11,331.0\end{array}$ \\
\hline Thrombocytopenia & ICD-9 & $287.5,287.49$ \\
\hline
\end{tabular}




\begin{tabular}{|l|l|l|}
\hline Acute ischemic stroke & ICD-9 & $\begin{array}{l}433.01,433.11,433.21,433.31, \\
433.81433 .91,434.01,434.11, \\
434.91,435 . x, 436\end{array}$ \\
& & $\begin{array}{l}430,431,432^{*}, 459.0,578^{*}, \\
784.7,786.3,998.11 \\
\text { (procedure-related bleeding) }\end{array}$ \\
\hline Bleeding & ICD-9, CCS & 785.51 \\
\hline Shock during admission & ICD-9, CCS & $37.68,37.61$ \\
\hline Use of assist device or IABP & ICD-9 & 423.0 \\
\hline Hemopericardium & ICD-9 & 37.0 \\
\hline Pericardiocentesis & ICD-9 & 423.3 \\
\hline Cardiac tamponade & ICD-9 & 47 \\
\hline $\begin{array}{l}\text { Diagnostic Cardiac } \\
\text { catheterisation }\end{array}$ & CCS & 44 \\
\hline CABG & & 45 \\
\hline PCI & CCS & 414.12 \\
\hline Coronary dissection & CCS & ICD-9 \\
\hline
\end{tabular}

ICD-9-CM: International Classification of Diseases, Ninth Edition, Clinical Modification; CCS: Clinical Classification Software 
Supplementary Table 2. Patient characteristics according to leukemia subtype

\begin{tabular}{|c|c|c|c|c|c|}
\hline Variable/Group (\%) & AML & CML & ALL & CLL & p-value \\
\hline Number of weighted discharges & 2278 & 3437 & 379 & 15600 & $<0.001$ \\
\hline \% within leukemia group & 10.5 & 15.8 & 1.7 & 71.9 & \\
\hline Age (years), \% median (IQR) & $74(66,81)$ & $74(65,82)$ & $65(53,72)$ & $79(71,86)$ & $<0.001$ \\
\hline Males, $\%$ & 72.8 & 62.6 & 73.6 & 64.4 & $<0.001$ \\
\hline Ethnicity, \% & +2 & & & & $<0.001$ \\
\hline White & 84.0 & 86.8 & 78.0 & 88.8 & \\
\hline Black & 6.4 & 6.3 & 8.1 & 4.8 & \\
\hline Hispanic & 6.2 & 4.3 & 7.4 & 3.2 & \\
\hline Asian/Pacific Islander & 2.9 & 1.5 & 0.0 & 0.5 & \\
\hline Native American & 0.3 & 0.3 & 0.0 & 0.2 & \\
\hline Other & 0.2 & 0.8 & 6.5 & 2.5 & \\
\hline STEMI, \% & 25.0 & 19.1 & 30.6 & 25.9 & $<0.001$ \\
\hline Elective Admission, \% & 7.1 & 5.9 & 5.0 & 6.9 & $<0.001$ \\
\hline Weekend admission, \% & 23.2 & 26.3 & 25.6 & 25.1 & $<0.001$ \\
\hline Primary expected payer, \% & & & 2 & & $<0.001$ \\
\hline Medicare & 74.9 & 77.0 & 60.8 & 82.6 & \\
\hline Medicaid & 2.5 & 1.9 & 3.5 & 1.1 & \\
\hline Private Insurance & 19.0 & 17.8 & 31.8 & 13.4 & \\
\hline Self-pay & 1.7 & 1.6 & 0.0 & 0.9 & \\
\hline No charge & 0.4 & 0.0 & 0.0 & 0.1 & \\
\hline other & 1.5 & 1.7 & 3.9 & 2.0 & \\
\hline $\begin{array}{l}\text { Median Household Income } \\
\text { (percentile), \% }\end{array}$ & & & & +2 & $<0.001$ \\
\hline $0-25^{\text {th }}$ & 22.0 & 25.6 & 19.7 & 23.3 & \\
\hline $26-50^{\text {th }}$ & 32.8 & 24.6 & 27.8 & 28.4 & \\
\hline $51-75^{\text {th }}$ & 22.5 & 25.9 & 19.7 & 24.8 & \\
\hline $76-100^{\text {th }}$ & 22.8 & 23.8 & 32.8 & 23.5 & \\
\hline \multicolumn{6}{|l|}{ Comorbidities, $\%$} \\
\hline Dyslipidemia & 45.8 & 47.7 & 47.9 & 45.7 & $<0.001$ \\
\hline
\end{tabular}




\begin{tabular}{|c|c|c|c|c|c|}
\hline Variable/Group (\%) & AML & CML & ALL & CLL & p-value \\
\hline Thrombocytopenia & 25.1 & 12.2 & 10.6 & 12.8 & $<0.001$ \\
\hline Smoking & 23.4 & 22.7 & 19.5 & 21.5 & $<0.001$ \\
\hline Previous AMI & 9.8 & 12.0 & 10.2 & 10.0 & $<0.001$ \\
\hline History of IHD & 65.4 & 76.9 & 71.6 & 71.9 & $<0.001$ \\
\hline Previous PCI & 10.7 & 19.0 & 18.8 & 10.9 & $<0.001$ \\
\hline Previous CABG & 11.9 & 11.5 & 8.7 & 9.8 & $<0.001$ \\
\hline Previous CVA & 2.4 & 5.5 & 5.1 & 4.3 & $<0.001$ \\
\hline Family history of CAD & 2.3 & 3.5 & 3.8 & 4.0 & $<0.001$ \\
\hline Alcohol abuse & 1.7 & 0.8 & 1.2 & 1.2 & $<0.001$ \\
\hline Deficiency anemias & 27.1 & 31.5 & 17.9 & 24.0 & $<0.001$ \\
\hline Chronic Blood loss anemia & 1.0 & 1.5 & 0.0 & 1.0 & $<0.001$ \\
\hline $\begin{array}{l}\mathrm{RA} / \text { collagen vascular } \\
\text { diseases }\end{array}$ & 2.8 & 2.8 & 5.3 & 2.1 & $<0.001$ \\
\hline Congestive heart failure & 1.0 & 1.1 & 6.3 & 1.5 & $<0.001$ \\
\hline Chronic pulmonary disease & 17.9 & 24.5 & 16.2 & 23.8 & $<0.001$ \\
\hline Coagulopathy & 29.0 & 15.8 & 11.5 & 16.1 & $<0.001$ \\
\hline Depression & 5.9 & 8.4 & 7.5 & 6.3 & $<0.001$ \\
\hline Diabetes & 25.8 & 28.7 & 33.7 & 26.8 & $<0.001$ \\
\hline Diabetes with complications & 3.8 & 8.1 & 10.1 & 5.3 & $<0.001$ \\
\hline Drug abuse & 1.5 & 0.9 & 1.0 & 0.4 & $<0.001$ \\
\hline Hypertension & 59.9 & 64.9 & 60.3 & 61.6 & $<0.001$ \\
\hline Hypothyroidism & 11.3 & 12.9 & 8.9 & 11.4 & $<0.001$ \\
\hline Liver disease & 0.8 & 1.4 & 2.4 & 0.9 & $<0.001$ \\
\hline Lymphomas & 2.1 & 1.0 & 4.0 & 2.8 & $<0.001$ \\
\hline Fluid and electrolyte disturbances & 24.9 & 26.2 & 16.3 & 23.1 & $<0.001$ \\
\hline Metastatic cancer & 0.6 & 0.5 & 0.0 & 0.9 & $<0.001$ \\
\hline Other neurological disorders & 4.2 & 5.2 & 2.4 & 6.1 & $<0.001$ \\
\hline Obesity & 5.9 & 8.5 & 9.6 & 5.6 & $<0.001$ \\
\hline Paralysis & 0.7 & 1.8 & 1.4 & 1.3 & $<0.001$ \\
\hline
\end{tabular}




\begin{tabular}{|c|c|c|c|c|c|}
\hline Variable/Group (\%) & AML & CML & ALL & CLL & p-value \\
\hline Peripheral vascular disease & 9.7 & 11.9 & 10.0 & 11.3 & $<0.001$ \\
\hline Psychoses & 1.8 & 1.5 & 2.3 & 1.4 & $<0.001$ \\
\hline Pulmonary circulation disorder & 0.0 & 0.3 & 0.0 & 0.2 & $<0.001$ \\
\hline Renal failure (chronic) & 19.9 & 30.4 & 15.8 & 21.8 & $<0.001$ \\
\hline Solid tumor without metastases & 2.3 & 2.7 & 1.3 & 2.8 & $<0.001$ \\
\hline Peptic ulcer disease & 0.0 & 0.3 & 0.0 & 0.0 & $<0.001$ \\
\hline Valvular heart disease & 0.2 & 0.3 & 0.0 & 0.5 & $<0.001$ \\
\hline Weight loss & 3.4 & 3.8 & 7.6 & 2.7 & $<0.001$ \\
\hline Hospital bed size, \% & 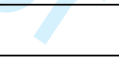 & & & & $<0.001$ \\
\hline Small & 10.5 & 11.0 & 8.6 & 11.2 & \\
\hline Medium & 23.6 & 24.3 & 23.2 & 23.4 & \\
\hline Large & 65.8 & 64.7 & 68.2 & 65.4 & \\
\hline Hospital Region, \% & & & & & $<0.001$ \\
\hline Northeast & 20.8 & 23.2 & 25.2 & 23.0 & \\
\hline Midwest & 28.4 & 22.0 & 14.0 & 25.1 & \\
\hline South & 32.7 & 37.5 & 45.0 & 34.9 & \\
\hline West & 18.0 & 17.2 & 15.8 & 17.0 & \\
\hline Location/ Teaching status, \% & & & 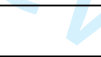 & & $<0.001$ \\
\hline Rural & 11.5 & 9.2 & 8.7 & 12.6 & \\
\hline Urban non-teaching & 34.5 & 41.9 & 36.1 & 40.4 & \\
\hline Urban- teaching & 53.9 & 48.9 & 55.2 & 47.0 & \\
\hline
\end{tabular}

AMI: acute myocardial infarction; CABG: coronary artery bypass graft; CAD: coronary artery disease; CVA: cerebrovascular accident

(stroke or transient ischemic attack); IHD: ischemic heart disease; IQR: interquartile range; STEMI: ST-elevation myocardial infarction

PCI: percutaneous coronary intervention; 
Supplementary Table 3. Adjusted odds ratios $95 \%$ confidence intervals of in-hospital adverse outcomes.

\begin{tabular}{|c|c|c|c|c|c|c|c|c|c|c|}
\hline & \multicolumn{2}{|c|}{ All Leukemia } & \multicolumn{2}{|l|}{ AML } & \multicolumn{2}{|l|}{ CML } & \multicolumn{2}{|l|}{ ALL } & \multicolumn{2}{|l|}{ CLL } \\
\hline Event/Group & $\begin{array}{c}\text { aOR } \\
{[95 \% \mathrm{CI}]}\end{array}$ & $\begin{array}{c}\text { p- } \\
\text { value }\end{array}$ & $\begin{array}{c}\text { aOR } \\
{[95 \% \mathrm{CI}]}\end{array}$ & $\begin{array}{c}\text { p- } \\
\text { value }\end{array}$ & $\begin{array}{c}\text { aOR } \\
{[95 \% \mathrm{CI}]}\end{array}$ & $\begin{array}{c}\text { p- } \\
\text { value }\end{array}$ & $\begin{array}{c}\text { aOR } \\
{[95 \% \mathrm{CI}]}\end{array}$ & $\begin{array}{c}\text { p- } \\
\text { value }\end{array}$ & $\begin{array}{c}\text { aOR } \\
{[95 \% \mathrm{CI}]}\end{array}$ & $\begin{array}{c}\text { p- } \\
\text { value }\end{array}$ \\
\hline MACCE & $1.26[1.20,1.31]$ & $<0.001$ & $2.81[2.51,3.13]$ & $<0.001$ & $1.34[1.19,1.50]$ & $<0.001$ & $1.32[0.90,1.94]$ & 0.155 & $1.06[0.99,1.11]$ & 0.055 \\
\hline Stroke & $0.71[0.64,0.80]$ & $<0.001$ & $0.47[0.30,0.73]$ & 0.001 & $1.04[0.81,1.33]$ & 0.768 & $0.78[0.31,1.99]$ & 0.609 & $0.68[0.59,0.78]$ & $<0.001$ \\
\hline Bleeding & $1.00[0.94,0.92]$ & $<0.001$ & $0.59[0.48,0.72]$ & $<0.001$ & $1.20[1.05,1.37]$ & 0.007 & $0.75[0.47,1.20]$ & 0.747 & $0.84[0.79,0.91]$ & $<0.001$ \\
\hline
\end{tabular}

MACCE: major adverse cardiovascular and cerebrovascular events: composite of mortality, stroke and cardiac complications 